7th International Symposium on the Biosafety of Genetically Modified Organisms

Beijing - China - October 10-16, 2002 


\title{
Towards the safe use of modern biotechnology: Report on the 7th International Symposium on the Biosafety of Genetically Modified Organisms held in Beijing (China) October 10-16, 2002
}

\author{
Ervin BALÁZS \\ Agricultural Biotechnology Center, 2101 Gödöllö, Hungary
}

\begin{abstract}
Along with the introduction of genetically modified organisms in the field, both biotechnology companies and academic institutes have conducted biosafety research in order to study the potential ecological impact of the modified organisms. With the growing concerns among various stakeholders, priority has been given to academic research on biosafety-related issues. For instance, the European Commission begun funding biosafety research of genetically modified plants in 1989, right after the first experimental releases of those modified crops. In the 5th Framework EC Research program biosafety research became a key action supporting 81 projects (for details see: http:// europa.eu.int/comm/research/quality-of-life/gmo/ index.html).

During this period, researchers gathered regularly to exchange ideas and their latest research results in this field at different workshops and also at a series of symposia held biennially since 1990. As early as the 5th International Symposium on the Biosafety of Genetically Modified Organisms, held in Braunschweig (Germany) in 1998, the Symposium's International Advisory Committee supported an idea to launch a new peer-reviewed journal, Environmental Biosafety Research (EBR), to facilitate communication in this research area, where controversial views are constantly expressed. It is hoped that EBR will contribute to clarifying the scientific terms of the debate, and that this will be useful for decision makers and other members of society. Another important event was the incorporation of a new learned Society, the International Society for Biosafety Research (ISBR), which was decided at the the 6th Symposium held in Saskatoon (Canada) in 2000 .
\end{abstract}

At the most recent Symposium, the first ISBR officers were elected: President, Alan McHughen (USA); VicePresident, Mark Tepfer (France); Secretary/Treasurer, Allison Snow (USA). Scientists who met at the 7th International Symposium in Beijing appreciated the quality of the first issue of EBR (a sample copy can be requested, and subscription purchased at: http:// www.edpsciences.org/ebr/) and the possibility of registration for membership of the newly-incorporated Society. Information on becoming an ISBR member, which gives the right to a reduced subscription price for EBR, can be obtained from Allison Snow (snow.1@osu.edu).

In Beijing, where more than 300 scientists registered from more than 30 countries, participants were able to learn not only the latest results on biosafety research, and in particular received first hand information about biosafety research in China, where GM crops are grown for commercial purposes. At this latest Symposium, the opening ceremony reflected the importance of the new technology, along with the safety considerations. This was followed by the different scientific sessions on new science for enhanced biosafety, consequences of gene flow, the possible implications of the releases of transgenic crops in centers of origin or diversity, the rationale of GMO regulations, biosafety considerations in China, transgenic insects for pest management programs and the effect of GMOs on microbial communities. The Symposium Programme Committee selected the above mentioned hot topics, among which two had outstanding interest for the audience. First, this was the first time that biosafety considerations on the release of transgenic insects were discussed, and second, the different questions raised by the detection of a $B t$ gene

E-mail: Balazs@abc.hu 
Overview of the 7th International Symposium on the biosafety of GMOs

in landraces of Mexican corn were debated. These sessions were followed by a field trip to Langfang (Hebei Province) to visit a transgenic $B t$ cotton field.

The opening lectures, delivered by the Vice Minister of China's Ministry of Science and Technology, followed by the Vice Minister of China's Ministry of Agriculture, emphasized that Chinese agriculture is the fourth largest in the world, feeding over $20 \%$ of the world population. This fact underlines that food safety and security are of great concern to Chinese society. The introduction of modern technology into agricultural practice could start a new green revolution by helping to meet with the growing food demand especially from the point of view of quality. China issued safety administration regulations on genetic engineering as early 1993. Implementing the regulations was started in 1996, by regulating field tests, environmental releases, and commercialization of transgenic plants. Since 1997, a total of 703 applications for biosafety evaluations were registered, and 517 were approved. Last year, ten lines of transgenic plants were approved, including the most important crops for China, such as rice, soybean and cotton. After the inaugural lectures, Axel Hebel, representing UNESCO, expressed the importance of biosafety research on a global scale, while Charles Kessler (EC) presented the view of the European Union member states, and the actions taken by the Commission, which supported the organization of this symposium and is strongly committed to the organization of the following ISBR Symposium in France in 2004.

The independent scientific sessions chaired by distinguished scientists from all over the world presented the state of the art of the selected topics. In this special section of EBR, the session chairs have been asked to collaborate closely with the speakers, in order to summarize the major achievements of their sessions. Plenary scientific sessions at 7th International Symposium on the Biosafety of Genetically Modified
Organisms

New science for enhanced biosafety

Joachim Schiemann

Consequences of gene flow

Allison Snow

Possible implication of the release of transgenic crops in centers of origin or diversity

Ariel Alvarez-Morales

Why regulate and how?

Julian Kinderlerer

Research and regulation on Biosafety of GMOs in China

Hongguang Wang (overview written by Yufa Peng and Shirong Jia)

Transgenic insects for pest management programs: status and prospects

Marjorie Hoy

Effects of GMOs on microbial communities

Kornelia Smalla 
Environ. Biosafety Res. 2 (2003) 37-41

(C) ISBR, EDP Sciences, 2003

\section{Session on:}

\section{New science for enhanced biosafety}

\section{Joachim SCHIEMANN, Chairperson}

Federal Biological Research Centre for Agriculture and Forestry, Institute for Plant Virology, Microbiology and Biosafety, Messeweg 11/12, 38104 Braunschweig, Germany

\section{SPEAKERS}

Site-specific genetic modifications for the post-genomic era

David Ow

Plant Gene Expression Center, USA

Elimination of marker genes by site-specific recombination

Jianru Zuo

Chinese Academy of Sciences, China

Means of preventing gene flow due to outcrossing

Ralph Bock

Muenster University, Germany

Biosafety aspects for molecular farming

Rainer Fischer

Fraunhofer Institute for Molecular Biology and Applied Ecology, Germany

Science-based approach to assessing the ecological risk of crops derived through modern biotechnology

Thomas E. Nickson

Monsanto, USA

E-mail: j.schiemann@bba.de 


\section{INTRODUCTION}

The scientific programme of the Symposium has been introduced by a session on "New science for enhanced biosafety". From the long list of exciting scientific approaches which have been developed since the 6th Biosafety Symposium in Saskatoon in July 2000, three topics were selected:

- Increasing the inherent biosafety of transgenic plants (three talks).

- Biosafety aspects for molecular farming (one talk).

- A science-based approach to assessing the ecological risks of transgenic crops (one talk).

The general considerations given in this overview paper reflect the personal view of the author. The overview of the excellent talks presented in Session 1 is based on the manuscripts kindly provided by the speakers. Where appropriate, the author makes use of original passages from the manuscripts.

\section{INCREASING THE INHERENT BIOSAFETY OF TRANSGENIC PLANTS}

One of the key topics in today's discussions about genetic engineering in agriculture is the next generation of transgenic plants which are more suitable especially for those markets where public acceptance of products derived from transgenic plants is rather low. Their outstanding characteristics:

- They are yielding high quality products, which can be produced in a more environmentally friendly and cost effective manner: plants resistant to pathogens, adapted to the growing site, and of high yield.

- Transgenic sequences are minimised to ensure function. Resistance to antibiotics and other sequences which are no longer of use have been eliminated. Plant host mutation is minimised by targeted insertion of gene sequences at pre-selected genome locations known to give no side-effects or unknown interactions.

- Expression of transgenic traits is limited to the tissues and to the conditions where they are needed. The transgene should be expressed according to what is a biological and an agronomical must. The desired expression of transgenic traits has to be ensured even under environmental stress and hence independent of plant specific regulatory factors.

- Production, testing, and selling of new transgenic plants is effected according to the consumers' demands, offering as much transparency as possible.

There are strategies available in the design of transgenic plants which can be considered best practice to reduce the identified risks of transgenic plants and to avoid some unidentified risks. At least four principle ways to achieve this can be described:

- Avoid or minimise the inclusion of superfluous transgenes or sequences.

- Avoid or minimise superfluous expression of the transgene and the impact of unwanted stress factors as well as plant regulation mechanisms on the transgene expression.

- Avoid or minimise plant host mutation by targeted insertion of gene sequences at pre-selected genome locations known to give no side-effects or unknown interactions.

- Avoid or minimise the dispersal of transgenes in the environment.

Based on recently developed enabling technologies and improved precision biotechnology tools best practice in the design of transgenic plants could help to reduce acceptance problems and to generate generally accepted solutions. Considering the principles of precision biotechnology early in the development of a transgenic plant can help to deal better with risk and uncertainty in evaluating the safety of transgenic plants. A large scale of approaches is available for which a case-by-case safety assessment is necessary. The timelines to practically use the enabling technologies vary according to approach and crop. It will take the industry some years to adopt these methods for product development across all crops. It may need a decade that best practice as described above becomes a general market reality. A set of criteria (maturity, resource intensity, regulatory familiarity and complexity, patents and market acceptance) for more systematic comparative assessments of current and future enabling technologies for plant transformation should be developed, combining R\&D-related, regulatory and commercial criteria. Informed and well-communicated policies on best practices for the design of transgenic crops will hopefully contribute towards improving information flow from citizens to research and from research to citizens to foster acceptance.

To avoid or minimise the inclusion of superfluous transgenes or sequences in transgenic plants, different approaches have been developed including elimination of marker genes by cotransformation, by site-specific recombination, or by transposition, whereas recombinases and transposases can be introduced into plants as DNA, RNA or protein. According to the point of view persistence of selectable marker genes in the field is unnecessary, undesirable, or unacceptable. "The Moor 
has fulfilled his duty, the Moor can leave". There are several good reasons to minimise transgenic DNA by marker gene elimination: (i) for subsequent transformation the use of the same selection system is not precluded - since valuable selection systems are limited for most crops, it is important to reduce the necessity for using different selectable marker systems for each transformation; (ii) accumulation of marker and regulatory sequences is avoided - regions of transgene homology which could result in transgene instability are minimised; (iii) risk assessment of marker genes and other transgene sequences to ensure the safety of new transgenic products is a costly process for both the applicants and the regulators - it would be reasonable to spend part of the necessary effort searching for alternatives; and (iv) marker-free products will have a higher market value. Developing and testing of a wide range of approaches is required since one cannot expect that a general solution for minimising transgene sequences while maintaining optimum function will be found. A very promising approach for "Elimination of marker genes by site-specific DNA recombination in higher plants" developed in Chua's laboratory was presented by J. Zuo. They have developed a chemical-regulated, site-specific DNA excision system. In this system, the resistance marker gene was placed between two copies of loxP sequence, which can be specifically recognised and cleaved by the DNA recombinase Cre. Expression of Cre was tightly controlled by a chemical-inducible promoter. The latter can be specifically activated by a chimeric transcription factor, whose activity is controlled by the mammalian hormone estrogen, a chemical with no detectable nonphysiological effects on plant growth and development. In transgenic Arabidopsis thaliana plants application of estradiol led to the activation of the chimeric transcription factor which then promoted a high level expression of Cre. The recombinase subsequently excised the loxP-sandwiched kanamycin-resistance marker gene and the other components of the system. Upon site-specific DNA excision and recombination, a promoter-less GFP reporter gene was brought directly downstream of a strong promoter, leading to GFP expression in markerfree transgenic plants. Genetic and molecular analyses indicated that the system is tightly controlled, showing high-efficiency inducible DNA excision.

To avoid or minimise plant host mutation by targeted insertion of gene sequences at pre-selected genome locations known to give no side-effects or unknown interactions, "Recombinase-directed transgene placement" will be a powerful approach. D. Ow reported that recombinase-mediated site-specific integration has been developed for several plant species, including rice and maize. The general scheme requires a first recombination site to be introduced into the genome to serve as the target site for the subsequent insertion of a second DNA molecule. Reports to date show that recombinase-directed site-specific integration can place a single-copy non-rearranged DNA fragment into the target site in 1 out of 3 selected events, a rate that is significantly higher than those reported for homologydependent insertions. Moreover, half of the precise insertions express the transgene at a predictable and reproducible level. This means that once a suitable target site is found, the plant line can be used for the subsequent delivery of trait genes. According to D. Ow the next challenge will be to develop an integrated strategy to stack and translocate DNA. Being able to append new DNA sequentially to a target site permits the continual use of a previously characterised chromosome location, which justifies the initial investment costs in identifying favorable chromosome targets. Stacking transgenic traits at a limited number of target sites would also be preferable to scattering transgenes all over the genome, as the clustering of transgenes expedites the introgression of bundled traits to elite cultivars, through a process mediated by the translocation of transgenes from one chromosome to another. In the first part of his talk, D. Ow proposed a strategy that permits the sequential and repeated delivery of new DNA to the genomic target, as might be expected if a transgenic plant line were to be improved over time through the sequential addition of new transgenic traits. In the second part he described a recombinase-directed introgression strategy to move the clustered transgenes from laboratory to field cultivars. D. Ow underlined that new tools permitting greater precision in genetic manipulations will invariably improve the efficiency of introducing new traits for crop improvement. With an ever-growing wealth of genomic data, it will not be long before crop plants will be engineered with multitudes of useful traits. How these genes are integrated and introgressed into cultivated varieties can expedite or impede the growth of the transgenic era. The immediate task ahead is to test the efficacy of the transgene stacking and translocation strategies. Providing that they be successful, suitable target lines in crop plants would need to be generated. This could be a major undertaking given the large number of different crop species where this technology may be applicable, and the large number of different cultivated varieties within a given crop. A concerted effort by interested parties would be much more preferable to independent efforts. The construction of target sites 
dictates future stacking options. If engineered with common elements, they can be shared among research and commercial communities.

To avoid or minimise the dispersal of transgenes in the environment, different "Means of preventing gene flow due to outcrossing" have been developed. R. Bock described selected scientific approaches to prevent unwanted transgene transfer from transgenic plants to non-transgenic plants as well as transgene flow from transgenic crops to related wild species. Three different strategies potentially suitable to ensure containment of transgenes were explained: (i) engineering apomixis into transgenic plants, (ii) use of male sterility, and (iii) engineering the plastid genome as an alternative site for transgene expression. Special emphasis has been placed by $\mathrm{R}$. Bock on transgenic plastids since transgene expression from the plastid genome offers attractive alternatives to conventional transgenic plants including high level foreign protein expression and transgene containment due to lack or strong reduction of pollen transmission.

Asexual forms of plant reproduction which, in spite of the absence of syngamy, give rise to the formation of viable seeds are collectively referred to as apomixis. Apomixis occurs naturally in over 400 plant species and is likely to have evolved several times independently. Elucidating the molecular mechanisms regulating apomixis and identifying the responsible loci potentially would facilitate the engineering of apomixis into crops. From the perspective of transgene containment, apomixis seems to be attractive: As apomictic reproduction is entirely independent of pollen, apomictic transgenic crops being male sterile theoretically could provide valuable containment. With the current acceleration of research on apomixis, a detailed understanding of the underlying molecular mechanisms may soon be a reality, followed by the design of promising strategies for engineering apomixis into transgenic crops.

In conventional plant breeding, three methods for the generation of male sterile plants are known: (i) mechanical emasculation, (ii) nuclear male sterility (nms), and (iii) cytoplasmic male sterility (cms). Gene technology has added another form of male sterility to the toolbox of plant breeders which may help to overcome the problem with segregation of the transgene locus and the male sterility trait. In principle, genetically engineered male sterility is similar to naturally occurring nuclear male sterility except that (i) engineered male sterility is dominant whereas natural nms is usually recessive and (ii) engineered male sterility allows coupling the transgenic trait with the sterility locus. The latter difference is of particular importance, as it makes segregation of the two loci highly unlikely - an essential prerequisite for providing high-level transgene containment.

Another possibility to prevent unwanted transgene spreading by pollen is to place the transgene not into the nuclear but into an organellar genome. A single plant cell contains many plastids and each plastid contains numerous (identical) copies of the plastid genome. Plastids and the plastid DNA are often transmitted in a uniparentally maternal fashion, although in few species biparental or even predominantly paternal plastid inheritance has been observed. In addition to improving containment, transforming foreign genes into the plastid DNA offers several additional attractions: (i) high levels of transgene expression and foreign protein accumulation; (ii) targeted transgene incorporation and absence of epigenetic effects; (iii) transgene stacking and efficient expression from operons; (iv) availability of efficient techniques for selectable marker elimination; and (v) simple transfer of transgenic traits between cultivars. The recent successful development of a plastid transformation system for tomato provides a first protocol for the generation of fertile transplastomic plants in a food crop with an edible fruit. In contrast to the usually low plastid gene expression levels in non-green tissues, chromoplasts in ripe transplastomic tomato fruits expressed the transgene to $\sim 50 \%$ of the expression levels found in leaf chloroplasts. Given the generally very high foreign protein accumulation rates that can be achieved in transgenic plastids, this system may provide the efficient production of edible vaccines, biopharmaceuticals and nutraceuticals in consumable plant organs and, simultaneously, provides containment of the plastid genome-encoded transgenes. For future prospects, combination of plastid transformation with naturally occurring cms may offer an attractive option to further improve transgene containment. Maternal inheritance of both the plastid transgene and the (mitochondrial) $\mathrm{cms}$ trait would greatly simplify crossing schemes and largely eliminate the need for the costly development and propagation of suitable restorer and maintainer lines.

\section{BIOSAFETY ASPECTS FOR MOLECULAR FARMING}

In his talk on "Biosafety aspects of molecular farming", R. Fischer highlighted the fascinating approaches of molecular farming to use plants for synthesizing antibodies and vaccines on an agricultural scale. This 
technology will help to bring recombinant antibody and protein therapeutics down in costs, without sacrificing their quality or safety. However, plant-derived products must be tested extensively to ensure the absence of potentially harmful constituents such as toxicants, pathogens, pesticides, herbicides, fungicides, heavy metals, anti-nutrients and allergens. Furthermore, the product itself must be rigorously characterized and compared to comparable materials produced in other systems. It is also necessary to consider environmental safety risks posed by gene transfer, gene expression, the production of foreign proteins in living plants and the presence of those proteins in decaying plant material. The biosafety aspects of molecular farming can therefore be divided into two major groups: the potential spread of transgenes and the potential negative effects of the expressed protein on the environment and the consumer.

One of the main priorities in molecular farming is keeping the transgene, and its encoded product, away from the human and animal nutritional chains. The simplest way to achieve this is to use a non-food and nonfeed crop, or a plant variety that allows identity preservation. Where a food or feed crop is used as the production host, containment strategies should be put in place to prevent transgene spread by seed and pollen dispersal. Recently, the North American biotechnology industry has adopted a broad moratorium on planting certain types of crops in major food-producing regions. The voluntary ban is designed to prevent the spread of specific transgenes into field crops likely to be used for food or animal feed.

\section{A SCIENCE-BASED APPROACH TO ASSESSING THE ECOLOGICAL RISK OF TRANSGENIC CROPS}

In his talk on a "Science-based approach to assessing the ecological risk of crops derived through modern biotechnology", T.E. Nickson underlined that new agricultural technologies need to be developed and prudently implemented since current practices have significant ecological and environmental impacts. The use of genetic engineering techniques to transfer traits useful in insect, disease and weed control have provided farmers with pest control solutions that are highly effective and yet very specific.

Obtaining regulatory approval is an essential part of the introduction of transgenic crops. A thorough, sciencebased assessment of a modified crop includes a rigorous ecological risk assessment as well as a detailed characterization of the product prior to conducting the assessment. T.E. Nickson described an approach that has been developed over the years to assess the ecological risks associated with crops derived through biotechnology. The approach is science-based, utilizing the basic framework of ecological risk assessment as developed by the US EPA. In particular, the potential risks associated with the modified plant, such as altered weediness, and the introduced trait, for example nontarget impacts and potential effects associated with gene flow, are evaluated in a systematic manner. Key questions concerning potential hazards and exposures are addressed and, where necessary, a tiered experimental approach is used to characterize risk. 


\section{Session on:}

\section{Consequences of gene flow}

\section{Allison A. SNOW, Chairperson}

Department of Evolution, Ecology, and Organismal Biology, Ohio State University, Columbus, OH 43210, USA

\section{SPEAKERS}

Crop-to crop gene flow: dispersal of transgenes during field tests and commercialization Baltazar Baltazar

Pioneer Hi-Bred International, Mexico

Gene flow from crops to wild relatives in Asia: case studies and general expectations

Baorong $\mathrm{Lu}$

Fudan University, China

Mitigating gene flow: herbicide resistant rice, introgression to weedy red rice, and mitigation strategies Jonathan Gressel

Weizmann Institute of Science, Israel

Agronomic effects of gene flow: multiple herbicide resistance in volunteer crop plants Linda Hall

University of Alberta, Canada

Ecological effects of pest resistance genes that disperse into weed populations Allison Snow

Ohio State University, USA

$\overline{\text { E-mail: snow.1@osu.edu }}$ 


\section{INTRODUCTION}

During the past decade, knowledge about the extent of gene flow from transgenic crops to wild, weedy, and cultivated relatives has increased dramatically. Many studies have documented gene flow, hybridization, and the persistence of crop genes in unmanaged populations. Examples of recent advances are illustrated in the following case studies:

- Wheat (Triticum aestivum) can hybridize spontaneously with jointed goatgrass (Aegilops cylindrica), a weed that occurs near wheat fields in the USA.

- Trace amounts of pollen from commercial rapeseed fields can be disperse least $3 \mathrm{~km}$ from their source and produce seeds on other cultivated rapeseed plants.

- Sunflower genes are able to spread and persist for many generations in populations of wild sunflower, which is an agricultural weed in the USA.

- Transgenes in commodity crops such as maize, soybean, and cotton are likely to cross international borders via seed mixing, grain imports, and unauthorized use of transgenic crops by farmers.

These types of studies illustrate that containment of transgenes is probably unrealistic for most commercially grown crops, and even a moderate degree of confinement may be difficult to achieve. Therefore, it is important to understand whether gene flow from transgenic crops could have undesirable consequences. This question can be addressed from several points of view, including human health, environmental, agronomic, economic, legal, and/or social concerns. The goal of this plenary session was to focus on the ecological and agronomic consequences of gene flow.

\section{GENE FLOW AND ITS CONSEQUENCES IN MAIZE AND RICE}

B. Baltazar and his coauthor J. Schoper presented recent work on cross-pollination between modern maize cultivars, local landraces, and wild teosinte (Zea mays ssp. mexicana). In the dry environments at their study sites in Mexico, maize pollen lost viability within 1-2 hours of dehiscence and cross-pollination was not detected $300 \mathrm{~m}$ from the pollen source. B. Baltazar reported that they could control the dispersal of maize pollen from small-scale field trials by using isolation distances, border rows, and detasseling methods. He argued that research involving transgenic maize should be allowed to resume in Mexico because it is feasible to prevent gene flow from small-scale experiments. This research could help resolve issues about the potential use of transgenic maize in its center of origin.

On a commercial scale, maize and teosinte potentially can cross-pollinate where they occur together and have overlapping flowering times in Mexico and Central America. Teosinte is regarded as an important germplasm source for maize and is sometimes planted as a forage crop, but it is also considered to be a weed in some areas. Experimental pollinations showed that it is much easier for teosinte pollen to sire seeds on modern cultivars than vice versa, suggesting that crop-to-wild gene flow via pollen could be less common than expected. More studies are needed to evaluate whether spontaneous hybridization between maize and teosinte is common, and whether transgenes that enter populations of teosinte might have unwanted consequences. With regard to landraces, B. Baltazar noted that Mexican farmers often encourage gene flow from modern cultivars to local landraces, and this "controlled introgression can be thought of as increasing diversity rather than causing any decrease in genetic diversity". He stated that greater precaution may be needed if studies show that the consequences of gene flow from transgenic crops are biologically significant, above and beyond the effects of gene flow from nontransgenic cultivars.

In Asia, transgenes have the potential to spread to wild or weedy relatives of crops such as rice, soybean, oilseed rape, bread wheat, and millets. B. Lu and coauthors presented an overview of crop-to-wild gene flow in rice. They examined hybridization between cultivated rice (Oryza sativa) and perennial wild rice (O. rufipogon), which is a source of wild germplasm for the crop. These species often occur sympatrically, have overlapping flowering times, and are partially interfertile. In field experiments, B. Lu detected crop-wild hybridization rates of up to $3 \%$. Several lines of evidence suggest that transgenes from cultivated rice could spread to wild populations of $O$. rufipogon, $O$. nivara (a close relative of $O$. rufipogon), and weedy $O$. sativa. B. Lu noted that a better understanding of how to assess and manage possible risks associated with transgene escape is needed.

J. Gressel reviewed evidence for historical and ongoing gene flow from cultivated to weedy forms of rice (O. sativa). Weedy rice can be a severe problem in cultivated rice fields worldwide, especially in regions where labor-intensive transplanting methods have been replaced by direct seeding. The trend toward greater use of direct seeding is expected to exacerbate problems with 
weedy rice and other weeds such as sedges and Echinochloa species. Transgenic herbicide-resistant rice could provide selective control of all these weeds. However, these transgenes are expected to spread to weedy rice within a few years, even with careful weed management and rotation of herbicides. Seed dormancy in weedy rice could allow it to overcome rotation methods for eradicating it.

J. Gressel is a strong proponent of transgenic strategies for delaying or preventing gene flow in this type of situation. He suggested designing transgene constructs that tandemly link desired crop genes that enhance fitness (e.g., transgenic herbicide or insect resistance) to transgenes that would reduce fitness in weeds without harming the crop (e.g., dwarfing, lack of seed shattering, or lack of seed dormancy). With this strategy, the persistence of transgenes in weed populations would be unlikely. Other methods for bioconfinement of transgenes include GURTs (genetic use restriction technologies, i.e., "Terminator"), traits that rely on inducible promoters to limit transgene expression, and chloroplast transformation, which reduces gene flow via pollen but not seeds. Ideally, two or more strategies would be employed simultaneously to provide long-lasting confinement of transgenic traits. J. Gressel concluded that "it would be unwise to release transgenic rice bearing genes that might enhance weedy rice fitness, unless effective failsafe mechanisms are utilized." In the USA, transgenic glufosinate-resistant rice (Liberty Link $^{\mathrm{TM}}$ ) recently was approved for commercialization without a biological confinement strategy. It remains to be seen whether careful management of this variety can delay the rapid spread of glufosinate resistance to weedy rice.

\section{TRANSGENIC HERBICIDE RESISTANCE IN RAPESEED (BRASSICA NAPUS) VOLUNTEERS AND CERTIFIED SEED}

L. Hall, described consequences of growing transgenic rapeseed in Canada, where herbicide-resistant varieties have been grown since 1986 . Over $80 \%$ of the rapeseed acreage in Canada is now herbicide resistant. Volunteer rapeseed is a common weed in Canada and elsewhere, partly because about $5 \%$ of the seeds remain unharvested and seeds can survive for 4-5 years in the soil. Two transgenic rapeseed varieties are resistant to glyphosate (Round-Up ${ }^{\mathrm{TM}}$ ) and glufosinate (Liberty ${ }^{\mathrm{TM}}$ ), respectively, and a nontransgenic variety is resistant to imidazolinones. Rapeseed plants in western Canada outcross at a rate of about $20 \%$, so "stacking" of resistance genes is expected to occur in both volunteer rapeseed and weedy Brassica rapa, which is partially sexually compatible with the crop. Natural crosspollination in farmers' fields has resulted in volunteer rapeseed plants with resistance to all three herbicides. However, this has not yet been reported in weedy B. rapa. L. Hall noted that tillage and auxinic herbicides such as 2,4-D are commonly used to control glyphosate-resistant and glufosinate-resistant volunteers.

Another consequence of gene flow in rapeseed is the inadvertent contamination of certified conventional seed. Canadian regulations for certified seed allow only $0.25 \%$ off-types, including genetic contamination, and this threshold is not always achieved. The extent of the problem is not fully known, but one study showed that the average percent of transgenic seeds in certified seed lots was as high as $0.40 \%$ for glyphosate resistance and $0.29 \%$ for glufosinate resistance. Most of the varieties that were tested in this study included detectable levels of transgenic herbicide-resistant seeds. This implies that stricter isolation methods are needed for during the production of certified seed.

Given the potential for transgenes to become established in cultivated, volunteer, and weedy Brassica populations, it is clear that careful rotation and monitoring of herbicides and herbicide-resistant crops are needed. Transgenic rapeseed is popular with Canadian growers because of reduced costs from less frequent tillage and reduced use of soil applied dinitroanaline herbicides. However, the economic and environmental advantages of current transgenic varieties may diminish over time.

\section{EFFECTS OF TRANSGENIC PEST RESISTANCE ON WEED POPULATIONS}

A. Snow and her coauthors focused on the question of whether transgenes that confer resistance to herbivores or diseases are likely to enhance the fitness and population dynamics of wild or weedy crop relatives. An important first step in this research is to determine whether natural populations that can hybridize with crops are exposed to the types of herbivores and diseases that would be thwarted by resistance genes from the crop. In many cases, the fitness consequences of particular resistance genes may be negligible in wild populations. Wild plants may be unaffected by the pest, or they may not be exposed to it. If wild plants are damaged by target pests, it is useful is to carry out fitness experiments using transgenic progeny from crop-wild crosses. For example, studies of $\mathrm{BC}_{1}$ wild sunflowers (Helianthus annuus) 
Overview of the 7th International Symposium on the biosafety of GMOs

showed that a transgene for lepidopteran resistance (cry1Ac) can be associated with reduced herbivory and more than $50 \%$ greater fecundity under natural levels of insect pressure. In addition, these investigators did not detect any fitness costs of the $B t$ transgene. Once it is known that resistance genes can enhance the fitness of wild or weedy plants, further studies are needed to assess whether these populations could become more widespread or invasive.

In general, little empirical information is available about the extent to which various transgenes could affect populations of wild or weedy relatives of crop plants. To some extent, this can be attributed to a lack of sustained collaboration between the seed industry and ecological researchers. Due to the difficult, long-term nature of research on plant population dynamics, A. Snow recommended fitness studies as a key element in assessing the ecological effects of pest resistance genes. From a regulatory standpoint, it is also useful to examine whether new transgenic constructs could have greater ecological effects than ongoing gene flow involving nontransgenic resistance traits. In some cases, the phenotypes of conventional versus transgenic resistance genes could be very similar, but dominant and highly effective transgenes such as cry1Ac might confer novel phenotypic traits that are remarkably beneficial to weeds.

To access this journal online: www.edpsciences.org 


\title{
Session on: \\ Possible implication of the release of transgenic crops in centers of origin or diversity
}

\author{
Ariel ALVAREZ-MORALES, Chairperson \\ CINVESTAV Irapuato, Apdo. Postal 629, Irapuato Gto., 36500 Mexico
}

\section{SPEAKERS}

Transgenes in maize landraces in Oaxaca: official report on the extent and implications Ariel Alvarez-Morales

CINVESTAV Irapuato, Mexico

Farmers' management of maize landrace diversity

Julien Berthaud

IRD/CIMMYT, Mexico

Concerns about the effect of transgene introgression in maize landraces and teosinte José de Jesús Sánchez-González

Universidad De Guadalajara, Mexico

Possible effects of transgenes on genetic diversity

Paul Gepts

University of California, Davis, USA

E-mail: aalvarez@ira.cinvestav.mx 


\section{INTRODUCTION}

The topic that was discussed previous to this session was the possible consequences of gene flow into wild relatives or other crop species related to transgenic crops already in use. It may be argued that gene flow of traits such as herbicide resistance among commercial crop varieties may be more of an agronomic problem than a problem to the wild environment, although it has also been proposed that if transgenic crops which are now resistant to more environment-friendly herbicides were to become useless because of weeds becoming resistant to multiple herbicides, agriculture would again become dependent on chemicals that have a higher impact on the natural environment. It is, however, commonly accepted that a potentially more damaging consequence of gene flow would be the transfer of certain transgenes to open pollinated crop varieties or sexually compatible wild species living outside the agronomic, and therefore not managed, ecosystem.

In Mexico the Ministry of the Environment has confirmed that transgenes have been found in maize landraces in the State of Oaxaca. However, a final report from the Mexican Biosafety authorities is still pending. In this report it is expected that information will be presented regarding the extent of the problem, its possible implications for the environment and for human and animal health, as well as what is being done and what will be done about this issue.

The first talk of this session, by A. Alvarez-Morales was meant to address this issue and comment on the official report that was expected to be available by the time of the symposium, however since this was not the case, the general situation on field trials and commercialization of transgenic crops was discussed, as well as some of the main factors that allowed the present situation to occur.

It was mentioned that to many agronomists and other professionals with knowledge about the history and development of agriculture in Mexico, the presence of transgenes in the landraces of maize was not a surprise, but rather was something that was expected to occur, although maybe not as soon as it actually happened. The basis for this assumption was mainly the large amounts of maize that Mexico imports every year from the US (which does not segregate GM and non-GM maize), and the fact that due to a variety of reasons, some of this maize is used as seed, although its main purpose is to serve as food or feed. During this talk, it was also mentioned that a preliminary assessment of the situation showed that there was nothing to indicate that the identity of the landraces was being threatened, which has been the main claim of NGOs, environmentalists and other groups in Mexico.

One of the reasons why the landraces have not been affected is that they are not genetically pure lines. They are managed by the farmer in a way that ensures that these lines are part of a constantly changing genetic mosaic whose phenotype is recognized by the farmer as a specific landrace because it fulfills specific requirements of color, size, shape, taste, etc. This type of management is also responsible for a very large variability within single landraces and for the accumulation of mutant and lethal alleles which are not under selection. It was interesting to hear from J. Berthaud that gene flow via pollen exchange was, in some cases, a welcome source of variability that also decreased the possibility of obtaining plants homozygous for these lethal or otherwise deleterious alleles. Therefore in these cases gene flow plays an important role in the preservation of viable landraces. This in turn led to the idea that any strategy for reducing gene flow as the means for restricting transgene dispersal, would have to be rigorously evaluated because it could have a serious effect on the genetic dynamics of the landraces by reducing a substantial source of variability.

In his talk, J. Berthaud also mentioned that due to the variability encountered among the landraces, the best approach for their preservation would be through in situ conservation programs, which would maintain the entire diversity found among the landraces, rather that trying to preserve a landrace through a collection of just a few individual accessions as representative of a particular landrace.

Since it was being proposed that gene flow in maize is an integral part of the "farmers genetic system", it was recognized that any transgenes from introduced varieties would find their way into the landraces. Therefore J. Berthaud also pointed out the need to devise strategies for remediation, in case transgenes that could find their way into the landraces were found to have negative effects, and it became necessary to return the crop to the non-transgenic state. Could this be accomplished through the restriction of gene flow in the landraces?, or maybe through the massive and continuous introduction of "clean" seed in the affected communities? These were questions to think about.

In the next talk, by J. Sánchez, a complete panorama about maize was presented to the audience, starting from the importance of maize in Mexico, not only as a staple 
crop but also as a central player on the culture and traditions of the Mexican people. The genealogy of maize was presented, together with an extensive description of many landraces and modern or commercial varieties. It was shown that the traits that have been successfully introduced into commercial varieties, and that have given rise to elite varieties, such as high quality protein, can already be found within the genetic richness of the landraces.

A clear take away message from this talk was that the main threat to genetic diversity in maize was not from transgenes, but rather through factors such as urbanization, artificial pastures and intensive livestock grazing, and the introduction of commercial hybrids that are displacing the landraces from the rural communities. This is already happening, and the question that was then asked was: how can society stop the farmer from replacing his landraces with higher yielding hybrids if this represents a social advantage to the grower?, and what mechanisms should be implemented to ensure that landraces could be conserved in situ while not denying the farmer the possibility of a better standard of living?

A further consideration, stressed by P. Gepts in his talk, was the fact that since the domesticated gene pool represents only a small fraction of the diversity present in the wild relatives, these are the materials that could and should be preserved, both in situ and ex situ. Furthermore, the value of these wild relatives in his opinion should be considered in a broad context that should include not only the usefulness of these materials to the plant breeder, but also their social, cultural and esthetic value.

Conservation was an issue that also seemed to be of concern to members of the audience, and questions and opinions were discussed as to what could be an effective way to promote in situ conservation of the landraces. It was proposed by a member of the audience that products derived from the landraces should be commercialized as part of an internationally recognized in situ conservation effort, and therefore they should bear an extra cost that could compensate the farmer for growing and maintaining these landraces, instead of the more profitable hybrids available. This idea was well received by the majority of the audience, and it may be worth pursuing, however it should be only a part of a comprehensive program of in situ conservation linked to mechanisms aimed to improving the economic and social conditions of farmers using these materials. Another possibility was the improvement of the landraces through the incorporation of transgenes that would enhance yield and bring them closer to the performance of competing hybrids, reducing in this way the need for the farmer to change his traditional materials in order to increase his income.

With respect to the possible effect that transgenes could have if transferred to the wild relatives or the landraces, it was difficult to predict any scenario where dramatic changes could take place. Nevertheless, it was a common point that research is still needed to answer many questions regarding issues such as unintended effects of a transgene, or a possible effect of insect resistance in the wild populations. There were other issues as well that were mentioned at several points during this session about concerns related to the release of GM maize. A major concern was about an eventual release of GM maize altered to produce industrial or pharmaceutical compounds. Even though industry is actively pursuing ways to ensure that such GM crops would be modified to eliminate or substantially reduce the possibility of gene flow, the fact that transgenes have appeared in the landraces in the southern states of Mexico, has sensitized the public to the idea that transgenes cannot be contained. This is becoming a growing public concern, which at least in Mexico would certainly become a point of debate against GM crops, which this time could involve not only the traditional NGOs but also other groups of society that are strongly opposed to the genetic modification and use of food crops for industrial or pharmaceutical purposes.

Finally, it was mentioned that since one of the major problems to carry out science-based risk assessment was the lack of data, it would be important for the current situation in Mexico, as well as future controlled releases of GMs, to subject these to monitoring. However, it was recognized that monitoring may actually be very difficult to implement, and that to this date there is no clear answer as to what should be the endpoints to monitor, for how long, where, etc. These are questions that need careful consideration, but it should also be considered that monitoring may provide only negative results, and these could never be proof that a theoretical, although improbable event, is not occurring.

In the case of Mexico, the notion of containment for a crop species or geographical isolation does not seem to be a valid approach, therefore it will be necessary to perform risk assessment assuming gene flow. Since Mexico is a country harboring many wild relatives of many important crops such as maize, potato, tomato, peppers, squash, etc., it is very important to begin collecting ecological data on the wild relatives in order to build a knowledge base on which to predict possible effects of transgenes in 
Overview of the 7th International Symposium on the biosafety of GMOs

these wild relatives. In the case of maize it is very important to begin conducting research aimed to answer questions such as: will the transgene present in the landraces be maintained?, will the farmer select these traits?, will the transgene be stably maintained or will it move in the chromosome?, are there effects on non-target organisms?
All these questions need to be answered, and for this the present unofficial moratorium on GM maize release should be lifted. The moratorium did not prevent gene flow and gene movement into the landraces. So far it has only prevented valuable research from being conducted, and thus it has delayed possible solutions to the problems or questions that are being asked.

To access this journal online: www.edpsciences.org 
Environ. Biosafety Res. 2 (2003) 51-56

(C) ISBR, EDP Sciences, 2003

\section{Session on:}

\section{Why regulate and how?}

\section{Julian KINDERLERER, Chairperson}

Sheffield Institute of Biotechnological Law \& Ethics, Law Department, The University of Sheffield, Sheffield S10 2TN, United Kingdom

\section{SPEAKERS}

The precautionary principle

Eric Schoonejans

Ministère de l'Environnement, France

The trigger is novelty

Desmond Mahon

Environment Canada, Canada

\section{Biosafety regulation in China}

Jingen Cheng

Chinese Ministry of Agriculture, China

Criteria for evaluating biosafety frameworks: objectives and standards

Terry Medley

DuPont Agriculture \& Nutrition, USA

E-mail: J.Kinderlerer@ sheffield.ac.uk 


\section{INTRODUCTION}

There have been many occasions where we have faced a litany of information on the regulation of biotechnology in individual countries during which reports have been made as to the number of applications received and the manner with which a particular set of applications was handled in a country or region. Although the data is always important, the use of conference time to present information which is often best provided in written form has not been seen to be useful by many of the participants at the meeting.

The Cartagena Protocol of Biosafety was agreed in February 2000 and to date 37 countries have ratified this international agreement. The Protocol will enter into force ninety days after 50 countries have either ratified or acceded $^{1}$, and it is therefore expected that it will be effective early in 2003. At that moment there will be a requirement on those countries to have in place a regulatory system for handling modern biotechnology (in particular living modified organisms that may have adverse effects on the conservation and sustainable use of Biological Diversity, taking also into account risks to human health ${ }^{2}$ ). Article $8 \mathrm{~g}$ of the Convention on Biological Diversity requires that member states as far as possible and as appropriate:

"Establish or maintain means to regulate, manage or control the risks associated with the use and release of living modified organisms resulting from biotechnology which are likely to have adverse environmental impacts that could affect the conservation and sustainable use of biological diversity, taking also into account the risks to human health". 3

A vast number of countries which do not have an effective regulatory system in place to handle both the internal use of transgenic organisms and import (or export) of these organisms will have very quickly to institute appropriate systems to ensure that the regulatory systems are in place and in particular, to provide mechanisms for risk assessment and risk management.

\footnotetext{
1 Cartagena Protocol on Biosafety to the Convention on Biological Diversity, Secretariat of the Convention on Biological Diversity, Montreal 2000, ISBN 92-807-1924-6 Article 37.

2 Cartagena Protocol on Biosafety to the Convention on Biological Diversity, Secretariat of the Convention on Biological Diversity, Montreal 2000, ISBN 92-807-1924-6 Article 1.

3 Convention on Biological Diversity Article 8, http:// www.biodiv.org/convention/articles.asp?lg=0\&a=cbd-08.
}

A question frequently posed is "Should governments regulate biotechnology, and in particular if so should we regulate "modern biotechnology" differently to traditional biotechnology and what is the trigger for regulating products of modern biotechnology". 4

The mechanisms and underlying principles which govern the many different regulatory regimes that have been introduced around the world are different. This makes the topic confusing, difficult to understand and, where trade is concerned, there is a clear lack of certainty as to how best to implement a regulatory system. Even though most of the OECD countries have instituted a regulatory regime, there are major differences in the way that they implement regulatory regimes. In particular, there are differences in relation to the "trigger" which identifies which organisms are covered by the regulatory system. In Europe, for example, the technique used to make the organisms acts as the trigger. Genetically Modified Organisms to which the legislation applies are defined in Article 2, paragraph (2) ${ }^{5}$ :

"genetically modified organism (GMO) means an organism, with the exception of human beings, in which the genetic material has been altered in a way that does not occur naturally by mating and/or natural recombination; Within the terms of this definition:

(a) genetic modification occurs at least through the use of the techniques listed in Annex I A, Part 1;

(b) the techniques listed in Annex I A, Part 2, are not considered to result in genetic modification".

The techniques currently listed as included in the definition include recombinant nucleic acid techniques which involve the formation of new combinations of genetic material where the genetic material is introduced from outside the cell(s) in which they do not occur naturally, new combinations produced using microinjection, macro-injection or micro-encapsulation, and even cell fusion (including protoplast fusion) or hybridisation techniques where live cells with new combinations of heritable genetic material are formed through the fusion of two or more cells by means of

\footnotetext{
${ }^{4}$ Desmond Mahon, during his talk at the 7 th International Symposium.

5 Directive 2001/18/ec of the European Parliament and of the Council on the deliberate release into the environment of genetically modified organisms and repealing Council Directive 90/220/EEC. Official Journal of the European Communities - 17.04.2001 - L 106, p. 0001 - 0038.
} 
Why regulate and how?

methods that do not occur naturally. In vitro fertilisation, natural processes such as: conjugation, transduction, transformation, and polyploidy induction are expressly excluded if they do not involve the use of recombinant techniques. In addition mutagenesis and cell fusion (including protoplast fusion) of plant cells of organisms which can exchange genetic material through traditional breeding methods are excluded.

The United States chose (in 1986) to handle this topic very differently. It was believed that the regulations should depend on the organism and the dangers that it may present rather than on the method by which it was made. The policy was based on a presumption that the new techniques available to modify organisms were "an extension of traditional manipulations that can produce similar or identical products". 6 The Coordinated Framework introduced in 1986 addresses concerns raised as to whether products made using modern biotechnology posed greater risks than those produced using traditional techniques. The "underlying policy question was whether the regulatory framework that pertained to products developed by traditional genetic manipulation techniques was adequate for products obtained with the new techniques. A similar question arose regarding the sufficiency of the review process for research conducted for agricultural and environmental applications". The US Government concluded that the existing laws were sufficient to allay any fears and provide adequate regulatory oversight. This has meant that the trigger for regulation is the possibility of adverse effects due to the introduced organisms, and in general therefore, the involvement of known pests or diseases in the manufactured organisms.

The Canadian Government decided that its regulatory system should be triggered by novelty, and that any new organisms, produced by whatever mechanism, should be regulated. They argued that "Novelty" or newness is an appropriate trigger for regulation.

Once an oversight system has been triggered, the approach to assessing and managing the risk associated with organisms in the environment has been very similar. "Risk/safety assessment involves the identification of potential environmental adverse effects or hazards, and determining, when a hazard is identified, the probability of it occurring. If a potential hazard or adverse affect is

\footnotetext{
6 Coordinated Framework for Regulation of Biotechnology; Announcement of Policy and Notice for Public Comment, Office of Science and Technology Policy, June 26 1986, Federal Register, Number 51, p. 23302.
}

identified, measures may be taken to minimise or mitigate it. This is risk management". 7 The OECD Report on Harmonisation or Regulatory Oversight in Biotechnology recognised that the major differences between the different jurisdictions that it investigated were the triggers.

In addition, the OECD report suggests that "Absolute certainty or zero risk in a safety assessment is not achievable, so uncertainty is an inescapable aspect of all risk assessment and risk management (OECD, 1993). For example, there is uncertainty in extrapolating the results of testing in one species to identify potential effects in another. Risk assessors and risk managers thus spend considerable effort to address uncertainty. Many of the activities in intergovernmental organisations, such as the OECD, address ways to handle uncertainty". 7

It was therefore decided that a focus of one of the symposia at the 7th International Symposium on the Biosafety of Genetically Modified Organisms should be the administration and regulation of living modified organisms and especially that the symposium should attempt to address many of the underlying principles that are basic to these very different regulatory approaches. It was agreed that papers would be invited on the Precautionary Principle, the concept of novelty and on the need for certainty and reliability of the regulatory process. In addition the regulation of biotechnology in China as an example of a regulatory system in a "developing" country was to be addressed. The Chinese experience on why and how to regulate the biosafety of genetically modified organisms was seen as important.

There were four presentations during the symposium. E. Schoonejans talked about the precautionary principle, D. Mahon about the concept of Novelty as a tool for regulation, T. Medley about criteria for evaluating biosafety frameworks and J. Cheng about regulation in China. The talks were deliberately kept short to allow a significant period of time for questions and comments from the audience.

\section{PRECAUTION}

There have been many arguments about the "Precautionary Principle" or "Approach". Europe has incorporated this concept into its legislation and it is a guiding principle to the Directives that form the legislative backbone

\footnotetext{
7 Report of the working group on Harmonisation of Regulatory Oversight in Biotechnology, OECD 2000, C(2000)86/ADD2, Paragraph 54, p. 18.
} 
for the regulation of Biotechnology. Article 174 of the EU Treaty (1993) says action in the environmental field "shall be based on the precautionary principle." There are many unknowns in trying to identify risk when using the products of biotechnology, not least those which affect the agricultural and wider environment when a new variety is introduced into the environment. "How should regulators, acting as society's surrogate, approach risk in the absence of certainty about the likelihood or magnitude of potential harm?"8 Miller argues that the definition of this "principle" is not clear, but that it is usually interpreted as meaning that regulatory systems should be instituted to prevent or restrict actions that raise possible threats of harm "even though there may be incomplete scientific evidence as to the potential significance of these dangers." Miller argues that precaution diverts attention from real risks to postulated risk - "Rules for gene-spliced plants and microorganisms [in the European Union] are inconsistent, discriminatory, and bear no proportionality to risk". There is a clear difference between the understanding of the term precaution in Europe and in North America, for in European legislation relating to the regulation of biotechnology it has been taken to require a "step-by-step" and "case-by-case" approach where each new organism is considered on its individual merits and if allowed is introduced "gradually" into the environment. Although the European Union bases its analysis of risk on available scientific evidence and recognises that risk assessment must be undertaken in independent, objective and transparent processes, "Many risks are complex and multifaceted. A new risk may emerge whose nature and extent may have never been identified before. The challenge is to characterise the risk and then, within the structure of the risk analysis process, identify the correct action needed to protect health or the environment, while aiming to ensure that there is consistency between measures and objectivity in the manner in which decisions are made". 9 Whether there is sufficient scientific information or not, decisions have to be made "here and now" 9 . Precautionary measures "shall be proportionate and no more restrictive of trade than is required to achieve the high level of health protection chosen in the

\footnotetext{
8 Miller H.I. and Conko G. (2001) "The Perils of Precaution" 818 Connecticut Avenue, NW, Suite \#601, Washington, DC 20006, Published by the Hoover Institution, http:// www.policyreview.org/jun01/miller.html.

9 Robert J. Coleman, Director General Health and Consumer Protection Directorate European Commission, January 2002: The US, Europe, and Precaution: A Comparative Case Study Analysis of the Management of risk in a Complex World.
}

Community, regard being had to technical and economic feasibility and other factors regarded as legitimate in the matter under consideration". 9

It is strongly held (at least in the area of Genetically Modified Organisms) that Europe is more precautionary than the United States. Many (particularly US Scientists) persist in believing that precaution means "stopping" the use of all genetically modified organisms until there is persuasive proof that they pose no significant risk to the environment or human health. Europeans, on the other hand, interpret precaution entirely differently, believing that the principle does not preclude use, but permits use with care and "monitoring" to ensure that unpredicted hazards do not occur.

E. Schoonejans provided the audience with many concepts of precaution and the philosophies that lie behind the approach taken by the European Union. D. Mahon, in his talk, indicated that the "basis for regulation is "consequence". In terms of regulation a consequence is an adverse effect, and preferably this adverse effect is linked in a causal manner to a characteristic of the regulated activity or material".

The speakers at the symposium attempted to address the many issues identified under the general title of "precaution" and to provide an insight into the differences that we are observing when different interpretations confuse. It was said that, when compared to many countries both those in Europe and those in North America are more precautionary than many other countries - the dictionary definition of precaution is "careful forethought to avoid harm or risk". 10

Precaution may inhibit innovation. T. Medley showed a photograph of the design team in the early days of Microsoft (1978), and asked whether any of us would have invested in this group of individuals. The balance between ensuring the safety of the environment and protecting human health and of allowing progress is important and should not be forgotten when applying precaution.

\section{NOVELTY}

If the trigger is not the method of manufacture, then it is often argued that either all new organisms or varieties of organisms introduced into the environment should be regulated, or none. "Canada chose to regulate on the basis of novelty. In Canada the analysis of the regulation of

\footnotetext{
${ }^{10}$ Roget's II: The New Thesaurus, Third Edition. 1995, Houghton Mifflin Company.
} 
Why regulate and how?

products of modern biotechnology and the policy choice underlying the Canadian regulatory framework concluded that products of modern biotechnology can be regulated under the same regulatory framework as traditional products and that the trigger for regulatory oversight was novelty". 11

In Canada biotechnology is defined as "the application of science and engineering in the direct or indirect use of living organisms or parts or products of living organisms in their natural or modified forms". ${ }^{12}$ This definition is inclusive and does not specify a technique for modifying organisms. The Canadian regulatory framework applies the concept of novelty as the trigger for regulatory oversight. In the Canadian Environmental Protection Act (CEPA), new is defined using a list of substances (Domestic Substances List DSL) as a starting point. Anything not listed is "new" and must be notified prior to import, manufacture (including growing) or use. Canada also defines a plant with novel traits as "new" for these purposes.

In the Canadian system, therefore, new products are evaluated and are identified as having no adverse impacts; are unacceptable because of their likely adverse impacts or are subject to conditions to manage these impacts. "Examples could be new varieties developed through traditional breeding techniques, or isolation of a new bacterial pesticide, or a new chemical product". 11 "The basis for the determination thus becomes an analysis of the product, and an analysis of the consequences, which in turn requires an analysis of the receiving environment". 11

D. Mahon asked a rhetorical question as to whether transgenic organisms can really be identified as new? In the answer he quoted S. Brenner who said in 1978:

"... it cannot be argued that this is simply another, perhaps easier way of doing what we have been doing for a long time with less direct methods. For the first time there is now available a method which allows us to cross very large evolutionary barriers and to move genes between organisms which have never had genetic contact". 13

He continued "What has resulted from modern biotechnology is a change in the definition of newness for organisms. The original basis of speciation (reproductive

\footnotetext{
11 Desmond Mahon, at the Symposium.

12 Federal Regulatory Framework for Biotechnology, 1993.

13 Wright S., 1994 "Molecular Politics-Developing American and British Regulatory Policy for Genetic Engineering 19721982”. University of Chicago Press, Chicago, ISBN 0226 91066-0, p. 76.
}

isolation) is no longer sufficiently refined. This may appear to be a big change, but the reality is that in terms of regulation we have not relied on the rough guideline of speciation for some time. New is not based only on the organism but also on the receiving environment, and on the trait, as is the case in hybrids. The regulatory system has recognized newness outside of phylogenetic considerations for some time".

Perhaps the most important part of the talk was his conclusion: "Can science support a hypothesis of novelty as the trigger for regulation of the products of modern biotechnology. To evaluate the approach several elements are considered, the organism and its character; the consequence of the modification; and the receiving environment. In each case novelty as the trigger, for both traditional and biotechnology products has been evaluated and the conclusion can be supported that whilst modern biotechnology does result in new organisms, the current framework for evaluating and managing risk can be used for these products, with the caveat that as science advances it changes the quality and the weight attached to the questions posed in the evaluation".

\section{PREDICTABILITY}

One of the problems that face many of the organisations and companies that are working on producing transgenic organisms is the uncertainty of obtaining regulatory approval in some areas of the world. Were the assessment linked only to a scientific evaluation, and provided that "most" of the scientific information is available, it could be argued that regulators in different parts of the world would reach the same conclusions or would have defensible reasons for coming to different conclusions. T. Medley argued that a regulatory system should encompass many important facets of modern life. Safety standards are paramount and should be the same world-wide. $\mathrm{He}$ asserted that current products that are made using modern biotechnology are as safe as (or safer than) their conventional equivalents. "...Teams of researchers assembled by CAST have reviewed and analyzed the published studies in the context of farming practices, and the results clearly show that soil, air and water quality are enhanced through the responsible use of current biotechnology-derived soybean, corn and cotton crops...". 14

There is a clear necessity to attain public confidence and therefore information must be made available to the

\footnotetext{
14 Source: Dr. Teresa Gruber, Council for Agricultural Science \& Technology, June 2002.
} 
public which is rational, credible, objective and factual. It is on these criteria (and arguably only these) that public confidence needs to be built.

In order to provide the necessary certainty to permit innovation, regulatory systems should science-based, with policy decisions being decided at a general level before individual applications are considered. The system ought to be consistent and hence predictable and easily understood both by those regulated and by the public. It is important that the system is transparent so that decisions and the processes by which they are made are clear and are available to any who want (or need) to know. The system should be effective and responsive to those who use it, but must be able to change as the science changes. It is important that any system introduced should address both national and international needs; import and export or living modified organisms should be covered by the regulatory system. ${ }^{15}$

In order to assure that a regulatory system is effective, it ought to (argued Medley) meet five criteria: Comprehensive, Commensurate, Transparent, Inclusive and Predictable.

The term "comprehensive" was intended to address the question "are we asking the right questions for the generation of data necessary to address safety or risk concerns"? "Commensurate" questioned whether the regulatory effort is justified in view of the identified risks and asked how to assure that we do not either over or under regulate. "Transparency" encompassed two concepts - those applying for permits to proceed with transgenic organisms need to know what is required of them, and for the general public it provides assurance. "Inclusive" allows for anyone to be part of the regulatory oversight and be able to comment to the regulatory authorities; "Predictability" was seen as crucial, and related to the decisions being made being within a know time-scale, being based on clear standards, all stakeholders being clear as to their role and the basis of decision being clear.

The manner in which some countries have filed to meet these criteria was discussed. Decision processes in which Ministers made decisions rather than officials was said to cause problems because of lack of predictability and it was suggested that in introducing new regulatory systems the need for these five criteria should be clear.

\footnotetext{
$\overline{15}$ Biotechnology, Second Edition, Volume 12: Legal, Economic and Ethical Dimensions, Terry L. Medley \& Sally L. McCammon, 1995.
}

\section{REGULATION IN CHINA}

The Chinese experience in regulating biotechnology was discussed as an example of why and how to regulate biosafety at a national level was introduced by J. Cheng. There have been many releases into the environment in China, primarily for field test or laboratory work. The work covers plants, animals and micro-organisms. It has been recognized that the new technology has to be employed carefully and that the introduction of regulatory systems has to be effective and appropriate. The Ministry of Agriculture has been involved for a long time in assuring that regulations are in place.

Regulatory processes need to be responsive to changes in the technology, especially in this field where change is so fast. The regulations, the review process and the decision making process need to be adjustable in these circumstances. In 2001 the Chinese State Council issued new regulations on the Safety of Agricultural GMOs. These include regulations relating to the safety assessment, import and labelling. Their purpose is to strengthen the safety administration, protect human and animal health, protect the environment and promote research. The Chinese Government chose to assess transgenic organisms on a case-by-case basis and stepby-step. It was agreed that the decisions should be based on demonstrable risks with reviews focusing on scientific questions and data. An expert panel was to be set up that would advise during the decision making process. It was considered important that the process should be "consistent, dynamic and transparent". Management of risks should be based on the risk assessments and could impose conditions on the manner of use of the organisms.

It was important that the risks and benefits of the use of the transgenic organisms should be communicated to allow informed decision making. The meeting was told that China considered it very important to have international cooperation and exchange in the regulation of biosafety.

\section{CONCLUSION}

This was a fascinating symposium that generated a great deal of discussion and comment. Scientists often remain sceptical that the administrators, regulators and general public do not often understand the many issues that impact on decisions. This symposium provided an opportunity to discuss, think and comment on the many differences between us. 


\section{Session on:}

Research and regulation on biosafety of GMOs in China

\section{Shirong JIA and Yufa PENG}

Chinese Academy of Agricultural Sciences, Beijing, China

\section{SPEAKERS}

Strategic approaches to biosafety studies in China

Yufa Peng

Chinese Academy of Agricultural Sciences, China

Studies on gene flow in China

Shirong Jia

Chinese Academy of Agricultural Sciences, China

Research and development of recombinant microbes and safety considerations in China

Dafang Huang

Chinese Academy of Agricultural Sciences, China

Economic impacts of plant biotechnology in China

Jikun Huang

Chinese Academy of Sciences, China

Environmental impact of Bt cotton: a case study from China

Kongming Wu

Chinese Academy of Agricultural Sciences, China

E-mail: jiasr@mail.caas.net.cn 
In China, public institutions dominate the research and development of agricultural biotechnology. Genetically modified (GM) insect-resistant cotton has been largely commercialized and small farmers have gained significant benefits from adoption of GM cotton. This situation has attracted much international attention and triggered the organizers of this Symposium to have a first China Session, which was chaired by Y. Wang. It should be noted that in addition, $\mathrm{Z}$. Chen presented "The status of agriculture biotechnology in China" in the opening ceremony and J. Cheng presented "Biosafety regulation in China" in the "Why regulate and how?" session.

GMO Biosafety research in China started in late 1980s, while agricultural biotechnology research was initiated in early 1980s. Risk assessment of GMO products was mainly done by developers. However, biosafety research on general issues and specific products were done by national and regional institutions. In recent years, both government and private sector-funded research on safety of GMO have been significantly increased. For example, since 2000, there have been four projects in the National Transgenic Crop Initiative, eight projects in the 863 National High-Tech Program, seven projects in the 973 National Fundamental Science Program, and three projects in the National Key Science \& Technology Program for the Tenth Five-YearPlanning. The overall aim of these projects is to promote the safe use of GMOs, while some projects may aim at enhancing knowledge of possible biological impacts on the environment and human health by corresponding basic research and the others may aim at providing a sound scientific basis for biosafety assessment, management and regulation.

Over the last decade there was a substantial amount of experimental data collected. The results and conclusions from these data have played a key role in promoting the development and commercialization of GM plants, animals and microorganisms. Field testing and commercialization of GMOs are regulated by the Ministry of Agriculture (MOA). Between March 1997 and December 2001, MOA approved over 500 applications for field trials, environmental test releases and commercial productions. Following the first approval of a delayed-ripening tomato, insect-resistant cotton varieties with Bt gene developed by CAAS and Monsanto were approved for planting in late 1997. Between 1998 and 2001, commercial planting approvals were granted to other GM crops such as virus-resistant sweet pepper, virus-resistant tomato, virus-resistant chili pepper, color-altered petunia and insect-resistant cotton with a combination of $B t$ and cowpea trypsin inhibitor
CpTI genes. Transgenic microbes approved for commercial production include nitrogen-fixing bacteria, biocontrol bacteria and vaccines for animal use. Over ten species of transgenic crops including rice, corn, wheat, soybean, oilseed rape, potato and poplar trees were approved for field testing.

The ecological and economic impacts of $B t$ cotton have been studied since 1995. The ecological studies have focused on the field performance of $B t$ cotton against Helicoverpa armigera, impacts on non-target insects and arthropod biodiversity, baseline for $H$. armigera susceptible to $B t$, resistance monitoring and management strategy, and mechanisms of $H$. armigera to develop resistance to $B t$. In northern China, transgenic insect-resistant cotton provided highly satisfactory control of cotton bollworm $(80 \%$ to $95 \%$ in different generations, seasons and locations during 1997 to 2001). The adoption of $B t$ cotton allowed insecticide spraying to be reduced by $70 \%$ to $80 \%$ (from 15 to 2 times on average). Due to reduced use of chemical pesticides, the biodiversity of insects and arthropods has been increased in the $B t$ cotton field. The increased natural enemies (predators in particular) also efficiently prevented cotton aphid from resurgence that would have occurred in non$B t$ cotton field with insecticide applications. The population density of cotton aphids, Aphis gossypii (Glover), was 443 to 1646 times lower in $B t$ cotton field than that in non- $B t$ cotton field with regular spray of both pyrethroid and organophosphorus insecticides. Meanwhile, resistance management for $B t$ cotton remains a serious concern because of the difficulty for small farmers to use a high dose/refuge strategy. A multicropping system consisting of wheat, $B t$ cotton, soybean (or peanut) and corn has been recommended as a natural refugia strategy for delaying the development of the pest resistance to $B t$ cotton. In terms of economic impact, based on surveys of hundreds of farmers in the Yellow River cotton growing region in northern China in 1999, 2000, and 2001, over 4 million small farm holders have been able to increase their cotton yield, reduce pesticide costs, reduce the time that they spend spraying toxic pesticides, and reduce incidents from pesticide poisoning. In a survey of farmers in Shandong and Shanxi provinces, the economic benefits were estimated to be RMB 2130/ha (about \$250/ha) on average including savings from reduced cost of labor and insecticide use.

Transgenic rice with insect resistance (CryIA, CpTI), disease resistance $(\mathrm{X} a 21)$, herbicide tolerance (bar, EPSPS), tolerance to other biotic and abiotic stresses and improved qualities has been developed. Therefore, study 
on the possible environmental impacts of these products is urgently needed, especially impact of gene flow in the centre of origin/diversity of rice. Since rice is a selfpollinated species in nature and pollen dispersal is mainly through wind, following factors affecting gene flow of crop-to-crop and of crop-to-wild relatives have been considered: (1) compatibility of sexual crossing and fertility of offspring derived from cross; (2) wind speed and directions; (3) distances from pollen donor plants; (4) amount of pollen produced from different pollen donor plants; for example, indica rice produces more pollens than that of japonica rice; and (5) pollen and stigma viability under different weather conditions. Particular attention has been paid to the pollen dispersal from transgenic rice to the male sterile (ms) lines used for hybrid rice production. Hybrid indica and japonica rice produced via three-lines (ms, maintainer and restorer) or two-lines (photoperiod-sensitive or temperature-sensitive $\mathrm{ms}$ and restorer) are now widely used in rice production in China. Since male sterile lines generally possess higher percentage $(12.2 \% \sim 79.0 \%)$ of out-stretched stigma for increasing the efficiency of hybrid seed production during flowering time, the outcrossing rate and gene flow frequency of transgenic rice to male sterile lines is much higher than that to common rice cultivars. In the case of side-by-side planting of transgenic rice together with male sterile lines of indica (Zhong 9A) or japonica (Ning 67A) rice, the gene flow frequency can be as high as $56.5 \%$ and $67.1 \%$ respectively.

Transgenic microorganism is another priority area. The products under development include the biocontrol agents such as entomopathogenic bacteria, virus, fungi, antagonistic bacteria against plant pathogens, the nitrogen fixing rhizobia and associative diazotrophus, the microbial products as feed additives with phytase, glucanase and xylanase, and the products for degradation of pesticide, cellulose, manure, plastics and aromatics. Based on risk assessment, two plant-associated microbial agents have been approved for a limited commercial production, 11 microbial agents approved for field testing releases in a relatively large scale and another 15 microbial agents approved for field trials. For example, Alcaligenes faecalis is a species of associative diazotrophus and a plant growth-promoting rhizobacterium with function of nitrogen fixation. The nifA and $n t r C$ genes were co-transferred into A1501, a wild type strain isolated from a paddy field. The resultant GM strain AC1541 was able to tolerant high $\mathrm{NH}_{4}^{+}$ $(10 \mathrm{~mm}, 65 \%)$ and when applied in rice and tomato/ cucumber, could increase yield by $8 \%$ and $11 \%$ to $33 \%$, respectively, or decrease the use of chemical fertilizer by $15 \%$ to $50 \%$. AC1541 has been approval for limited commercialization as a new bio-fertilizer in Northern China. Another example is Bt-containing microbial biocontrol agents. Since 1997, Chinese scientists have identified and cloned 36 cry and cyt genes from Bacillus thuringiensis, which accounted for one-third of the total $B t$ genes described worldwide in the same period. WG001, a GM strain of B. thuringiensis with high toxicity to Lepidopteran insect pests (cotton bollworm, diamondback moth) has been approved for commercial production.

In conclusion, China has made some progress in agricultural biotechnology and biosafety assessment. However, further study is needed to keep up with the rapid development of this new technology. 


\title{
Session on:
}

\section{Transgenic insects for pest management programs: status and prospects}

\author{
Marjorie A. HOY, Chairperson \\ Dept. of Entomology \& Nematology, University of Florida, P.O. Box 110620, Gainesville, FL 32611, USA
}

\section{SPEAKERS}

Analysis of risks of transgenic insects for pest management: past and future guidelines Marjorie A. Hoy

University of Florida, USA

Transformation of mosquito vectors of disease: goals and risk analyses

Chris Curtis

London School of Hygiene and Tropical Medicine, UK

Transgenic pink bollworms: evaluation of risks of releases in genetic control projects John Peloquin

University of California Riverside, USA

Chagas disease vectors that do not transmit the disease agent

Ravi Durvasula

Yale University School of Medidine, USA

Transgenic Mediterranean fruit flies for sterile insect release programs

Alan Robinson

FAO/IAEA Agriculture and Biotechnology Laboratory, Austria

E-mail: mahoy@ifas.ufl.edu 
This session was the first to cover the topic of transgenic insects in any of the International Symposia on the Biosafety of Genetically Modified Organisms. The objectives were to provide an overview of the goals of various programs around the world that would involve the use of transgenic insects or other arthropods in applied pest management programs. The five speakers were asked to review the goals of programs and the risk issues that might be associated with specific transgenic insects. Although the session did not include speakers representing all the programs in progress, it provided an overview of the diversity of goals, methods, and progress towards implementation.

Genetic modification using recombinant DNA methods can now be used, almost routinely, to transform pest and beneficial insects. Goals include modifying mosquitoes, and other insects that transmit human and animal diseases, so that they are unable to transmit the causal pathogens. Recombinant DNA methods could improve genetic control programs by producing sterile male insects or producing only females. Other goals include producing honeybees that are disease resistant and silk moths that produce new types of silk. Some insects are being transformed to produce drugs and vaccines. Natural enemies used in biological control programs could be modified to enhance their effectiveness in several ways.

The session began with an overview by M. Hoy, in which she noted that risk assessments in the USA must be conducted prior to releasing transgenic insects into the environment for short term experiments. No guidelines are available for risk assessments of transgenic insects prior to their permanent establishment in the environment, which is a goal of some genetic manipulation programs.

Potential risk issues to be resolved prior to releases include whether: the inserted gene(s) (trait) is stable; the traits (especially pesticide or antibiotic resistance genes) can be horizontally transferred to other populations or species; released insects will perform as expected with regard to their geographic distribution, host or prey specificity and other biological attributes; released insects will have unintended environmental effects; and, in the case of short-term releases, the released insects can be recovered from field sites. Risk assessments of fitness and host specificity are relatively easy to assess in the laboratory, but the potential risks of horizontal gene transfer and unintended effects on ecosystem function are much more challenging.

In the USA, permission to release a transgenic insect will have to be obtained from (several) regulatory agencies. Two releases of transgenic arthropods have occurred in the USA; one of a predatory mite (Acarina) that contained a lac Z marker gene and one of a pink bollworm moth that contained a green fluorescent protein gene. Releases were made into small plots and were intended to be short term experiments. Current regulations of the U.S. Department of Agriculture require the researcher to retrieve all transgenic arthropods from the environment at the end of the experiment.

If transgenic arthropod strain(s) perform well and risk assessments are completed satisfactorily, permanent releases into the environment may be allowed, but U.S. guidelines for such releases are lacking. Many pest management programs, especially those involving replacement of pest populations by a transgenic population, will require permanent establishment of the genetically modified strain (or of the transgene in the wild population) in the environment. Several drive mechanisms, including the release of active transposable elements or symbionts such as Wolbachia, have been proposed to insert genes into populations, but analyses of the potential risks of such drive mechanisms have not been carried out.

M. Hoy concluded with a plea that international guidelines be developed for risk analyses of transgenic arthropods because most are highly mobile and could move beyond individual countries' boundaries. Such guidelines would provide an impetus to the deployment of transgenic arthropods in pest management programs.

The second speaker was C. Curtis, who presented a talk on "Possible ways of using transgenic mosquitoes for malaria or dengue control and risk assessment". The problems of insecticide resistance in some mosquito populations and the difficulties of implementing traditional control methods justify the development of improved control methods, including, potentially, the use of transgenic insects to eradicate wild populations of these vectors of disease. The use of transgenesis to improve sterile insect release programs might be achieved by improving methods for separating the sexes in mass rearing factories so that males only are produced. One such method, called RIDL, might involve using a dominant lethal gene associated with a female-specific promoter so that expression of the dominant lethal is switched off so long as a particular nutrient is provided to the breeding stock; when, however, insects are being reared for release the nutrient could be removed, causing the death of all females. This would reduce costs of producing the millions of sterile males needed for control programs and reduce the likelihood of releasing females that could bite or transmit disease. Risk issues associated 
with the RIDL method include the need to: ensure that only males are released; eliminate any revertants in the breeding stock; evaluate the risk of horizontal gene transfer of the transgene(s); communicate clearly with the human population about the goals of the proposed control program.

The development of Plasmodium-refractory strains (strains that cannot transmit malaria) by transgenesis also was reviewed, and the difficulty of ensuring that the refractory trait is tightly linked with the "drive" mechanism used to insert the trait into the wild population was noted as a risk issue. Other potential risks associated with this control approach include the possibility of resistance to the refractory gene developing in Plasmodium, which would result in program failure. Another issue of concern was the importance of testing the transgenic mosquitoes to confirm that they are not susceptible to (or vectors of) pathogens other than Plasmodium as a result of undergoing genetic modification. Curtis concluded that the best chance of using transgenic mosquitoes may be "against urban vector populations surrounded by a different species in rural areas", because the logistics of deploying a complex genetic control program throughout the vast areas of Africa are daunting.

The third speaker was J. Peloquin, who gave the presentation "Field trials, the permitting process, comments and risks", and provided an overview of a project involving a transgenic pink bollworm, which was genetically modified using the transposable element piggybac to contain a modified version of the green fluorescent protein gene as a marker. The pink bollworm, Pectinopora gossypiella, is an important pest of cotton and has been the target of a sterile insect release program in California for some time. The initial objective of the program is to develop pink bollworms that can be identified readily by program managers in the sterile insect release program.

The field test of the bollworm strain with a marker gene required a lengthy risk assessment. The transgenic strain containing a green fluorescent gene construct was developed in March 1998; permission to move the transgenic strain from California to Arizona was given in March 1999 by the US Department of AgricultureAPHIS. A draft application to release was submitted in January 2000 to freely release (not into cages) the transgenic pink bollworms into the field site. This application to release was reviewed by the Arizona State Department of Agriculture and the US Department of Agriculture and comments by the public followed which resulted in a modified protocol in which the transgenic bollworms were released into cages.
Releases of the transgenic pink bollworms began October 5-16, 2001 and additional releases occurred during the summer of 2002. Releases were performed in a 3-acre cotton field in Arizona into cages within a plot surrounded by chain-link fencing to limit access by humans and animals, and the site was guarded to prevent vandalism. Safeguards to prevent the accidental escape of the transgenic insects from the cages included: pheromone traps were placed at the edges of the field to capture escaped insects; the field was treated with sterile pink bollworms three times a week; wings of the transgenic females were clipped to prevent them from flying away should they escape the cages; females were restrained during the experiment in "mating stations"; at the end of the experiment, cotton bolls from the release field were destroyed; only irradiated transgenic males were released. The goals of the field trial were to: compare the transgenic and nontransgenic males' responses to pheromones in the field; compare the longevity of the two types of males in the field, and compare the ability of the two types of females to solicit and mate with the two types of males in the field.

One concern raised by reviewers of the proposed releases was the possibility of horizontal gene transfer. J. Peloquin also discussed various statistical and experimental methods for analyzing this, expectedly, rare event.

A. Robinson presented a talk on "Transgenic Mediterranean fruit flies for the sterile insect technique". The Sterile Insect Technique (SIT) is used to suppress, eradicate or prevent the establishment of Mediterranean fruit fly (Medfly) populations. Currently, recombinant DNA methods could be expected to improve three aspects of this effective pest management tactic: (1) produce improved male-only strains for release; (2) introduce a phenotypic marker into the Medfly to replace the use of fluorescent dye for marking released insects (which is an important operational aspect of monitoring the progress of an SIT program); and (3) develop transgenic strains that exhibit a dominant lethality in the field after release so that irradiation is no longer required to induce sterility in the released males (the most distant goal).

If transgenic Medflies are released that have been sterilized in a traditional manner by irradiation, they cannot become established in the environment and the primary risk might be the horizontal transfer of the transgene to other organisms. Because of concerns about horizontal gene transfer, the use of antibiotic or cell death genes should be avoided in developing transgenic Medflies. If, however, fertile transgenic males are 
released that transmit genes to induce death in the embryos of wild females fertilized by these males, an alteration in the lethal system in the released Medflies could allow transgenes to leak into wild populations. Studies will have to be conducted to evaluate transgene stability and how horizontal transmission could be minimized. Research is needed to understand epigenetic interactions that might result in unintended or unexpected transgene activity or repression. New gene transfer systems are required that would allow targeted insertion to reduce the problems of random insertion.

The final speaker was R. Durvasula, who discussed "A paratransgenic strategy for control of Chagas disease." Paratransgenesis is the genetic manipulation of commensal or symbiotic bacteria that reside within arthropod hosts. The bacteria can be transformed to produce molecules that interrupt transmission of a target pathogen of humans, other animals, or plants.

The example provided was that of Rhodnius prolixus, a reduviid bug vector of Chagas disease, which is caused by Trypanosoma cruzi. This disease kills over 50000 people annually and nearly 90 million are at risk for the disease in Central America and parts of South America. At present, neither a cure nor a vaccine exists for Chagas disease. The transformation of an actinomycete gut symbiont, Rhodococcus rhodnii, with a cecropin A gene can result in the death of the infective stages of T. cruzi because $R$. rhodnii is an extracellular, intraluminal symbiont in the hindgut of the bug, which is where the infective stage of the pathogen occurs. Other goals of the program include developing engineered antibodies that could be produced by the gut symbiont. Delivery and spread of the transgenic symbiont among natural populations of the bug could be achieved by spreading a simulated fecal paste containing the symbiont, called Cruzigard, in the environment where the bugs hide. If the bugs feed on Cruzigard, they may retain the engineered gut bacteria, which would then produce the antibiotic or antibody, reducing or eliminating the ability of the bug to transmit the trypanosome.

Potential environmental implications of this diseasecontrol strategy include the potential toxicity of the Cruzigard bacteria to humans. Stability of the transgenes and horizontal gene transfer need to be assessed; the likelihood and effect of gene transfer to nontarget bacteria or to nontarget arthropods needs will be assessed.
In concluding remarks, M. Hoy stated that "The insects are coming", meaning that biosafety research on transgenic arthropods should become an important component of this International Symposium in future years. It is essential that regulatory issues be resolved and planning for appropriate risk assessments be initiated so that programs for managing serious arthropod pests with biotechnological methods are not delayed unnecessarily. Furthermore, international risk assessment guidelines should be developed for transgenic insects. Because insects are highly mobile, they do not recognize international borders and could readily move throughout the world. Compared to transgenic plants and microbes, transgenic insects make the issue of "gene flow" of special relevance. In fact, because many proposed pest management programs rely on the transgenic arthropod population mating with wild populations and persisting in the environment, transgenic arthropods will likely elicit high levels of scrutiny before they can be implemented in pest management programs.

Based on these presentations, the first transgenic insect to undergo risk analysis and implementation in a practical pest management program might involve the release of sterile insects (sterilized in a traditional manner) that contain a transgenic marker gene. Such sterile transgenic insects could not permanently establish in the environment and, as a result, horizontal movement of the marker gene would be unlikely. Even if the marker gene were to move horizontally, the consequences are expected to be minimal. Concerns about releases of transgenic insects that are refractory to disease transmission are expected to be much greater and extensive research is needed to assess the potential consequences of such releases, especially those that would involve permanent establishment in the environment.

What, if anything, is unusual about risk analyses of transgenic insects? The permanent establishment of transgenic insects in the environment, which is key to the success of some proposed pest management programs, means that issues of stability and fitness could be greater with transgenic insects than with transgenic crops, which are protected and cared for by farmers. Furthermore, releases of transgenic insects raise risk issues more like those associated with transgenic fish, because many insects are able to disperse over large distances and could establish permanently in new and undesired environments, causing negative ecosystem effects. 


\section{Session on:}

\section{Field releases of genetically modified micro-organisms}

\section{Kornelia SMALLA, Chairperson}

Federal Biological Research Centre for Agriculture and Forestry, Institute for Plant Virology, Microbiology and Biosafety, Messeweg 11/12, 38104 Braunschweig, Germany

\section{SPEAKERS}

Exploitation of genetically modified Pseudomonas for industrial ecology applications

Fergal O’Gara

National University of Ireland, Ireland

Why monitoring the fate of microbial inoculants and their impact on soil microbial communities is needed?

Kornelia Smalla

Biological Research Centre for Agriculture and Forestry, Germany

Monitoring microbial inocula, activity and impact on ecosystem function and soil microbial diversity Mark Bailey

CEH-Oxford Virology \& Environmental Microbiology, UK

Fate of GM rhizobial inoculants: lessons from Europe and elsewhere

Penny Hirsch

Rothamsted Research, UK

Monitoring the fate and ecosystem effects of genetically modified Pseudomonas putida producing phloroglucinol and phenazine in wheat rhizosphere

Eric Smit

National Institute of Public Health and the Environment, The Netherlands

$\overline{\text { E-mail: k.smalla@bba.de }}$ 


\section{INTRODUCTION}

The last session of the 7th International Symposium on the "Biosafety of genetically modified organisms" was devoted to biosafety research accompanying field releases of genetically modified micro-organisms (GMM). The session reflected the tremendous research efforts supported by different EU programmes (BAP, BRIDGE, BIOTECH) and national European biosafety research programmes to develop and use new molecular tools for monitoring the fate and efficacy of bacterial inoculants and their impact on indigenous soil microbial communities. Plant growth promoting rhizobacteria (PGPR) are of increasing importance as inoculants for bio-fertilisation, bio-stimulation and biological control of plant pathogens in sustainable agriculture. However, the success of applications of biological control strains requires a better understanding of the biotic and abiotic factors affecting the fate of microbial inoculants as well as the dynamics of microbial communities in the rhizosphere. The highly complex interactions between rhizobacteria, plants and soil made predictions on the fate and activity of microbial inoculants difficult if not impossible. The presentations given in this session reflected the impressive progress made over the last decade in developing molecular tools which allow to open the "black box" of microbial communities in bulk and rhizosphere soils. In particular, the introduction of reporter genes by means of gene technology has greatly facilitated the tracking of the survival and activity of introduced bacterial inoculants. Thanks to the use of reporter genes which enable a specific and sensitive detection of GMM released into the agro-ecosystems we have learned a great deal about the fate of bacterial inoculants and horizontal gene exchange processes in the phytosphere or in soil.

In their talks F. O'Gara, M. Bailey, and E. Smit reported about field releases with Pseudomonas fluorescens or Pseudomonas putida strains which were modified to introduce marker genes and/or to improve their biocontrol properties. The presentation by P. Hirsch summarised the findings of several releases of rhizobial inoculants in different parts of Europe. The talk given by $K$. Smalla aimed to assess the tools presently available to monitor the identity of microbial inocula and their fate and impacts on the soil microbiota, and to illustrate their use e.g. for monitoring genetically modified PGPRs used in China. The major findings and conclusions from these talks are summarised here.

\section{MOLECULAR TOOLS FOR STRAIN CHARACTERISATION AND CONFIRMATION}

Correct inoculant strain identification is crucial for risk assessment and should nowadays be based primarily on the complete sequence of the $16 \mathrm{~S}$ rDNA. In several cases PGPR strains had to be re-named, e.g. the PGPR strain Alcaligenes faecalis used in China is now renamed Pseudomonas stutzeri. The first and crucial prerequisite for the safe and successful use of PGPRs is that the strain identity and the presence and expression of the genetic modification are regularly confirmed, in particular when PGPRs are grown in large-scale fermenters and used for large-scale applications in the field. While in the past selective plating has been used primarily for strain confirmation, nowadays molecular fingerprinting techniques such as BOX or REP-PCR allow a rapid and reliable confirmation of the strain identity. An obvious advantage inherent to GMM in contrast to non-GMM is that PCR-based detection systems can be defined that allow specific detection of the genetic modification. The experience with PGPR strains from China showed the importance of the availability of reliable tools such as PCR primer systems specific for the transgenic construct, reference material of the genomic DNA, as well as a molecular fingerprint for monitoring PGPR strains applied in agriculture in large scale.

\section{SURVIVAL AND COLONISATION CAPACITY OF GMM}

Genetically modified rhizobial inoculants released in different regions in Europe have shown that the successful establishment of rhizobial inoculants varied a lot depending on the soil and climatic conditions (P. Hirsch). At Rothamsted, populations of the symbiotically-competent Rhizobium leguminosarum strain RSM2004 declined sharply in the months following application, but then stabilised, although at two other sites the same inoculant could not be detected the year following application. Even 15 years after the initial release of Tn5-marked $R$. leguminosarum and eight years after the release of a Gus marked strain at Rothamsted, the GMM strains are detectable although in relatively low numbers. A second GM $R$. leguminosarum strain (CT0370) lacking a symbiotic plasmid (which carries genes for host plant nodulation and nitrogen fixation), was released at the same site subsequently. It survived with higher numbers than RSM2004 in bulk soil, but appeared to compete less well to colonise roots of both host legumes and non-host plants. This indicates that the 
Field releases of genetically modified micro-organisms

symbiotic plasmid may confer a survival advantage in the rhizosphere. Long-term survival was also observed for Sinorhizobium meliloti strains marked with a luciferase gene $(l u c)$ which were released at two field sites in Germany. In the presence of indigenous rhizobial populations, the inoculants have to compete for nodule formation and form only a proportion of the root nodules. Where there are very low competing populations of indigenous rhizobia, spread of inoculants from the site of application to host plants in adjacent plots has been observed. In contrast to rhizobial GM inocula, field studies with biocontrol strain Pseudomonas fluorescens SBW25 showed that although the strain effectively colonised the roots and leaves of sugar beet plants, it was not detectable in soil the following spring. The survival of phenazine-1-carboxylic acid (PCA) producing variant of $P$. fluorescens SBW25 was analysed in the rhizosphere of different crop plants. Inoculant strain densities found in the rhizosphere of pea and wheat were higher than for sugar beet plants, indicating a plantdependent establishment of inoculant strains in the rhizosphere.

Field experiments performed with $P$. putida WCS358 strains that were modified to produce the antifungal compounds PCA and 2,4 diacetylphloroglucinol (Phl) showed in all years a decline of the inoculant strains from about $10^{7} \mathrm{CFU} . \mathrm{g}^{-1}$ of rhizosphere sample to $10^{2}-$ $10^{4}$ CFU.g ${ }^{-1}$ at harvest, and to near the detection limit $\left(10^{2}-10^{3}\right.$ CFU. $g^{-1}$ rhizosphere sample) one month after harvesting (E. Smit). In general, no indications were found that the fitness of the GMMs was affected by the genetic modification.

\section{HORIZONTAL GENE TRANSFER}

In the studies presented by P. Hirsch and by M. Bailey, horizontal gene transfer from the GMM to the indigenous bacteria and vice versa was a major focus. No evidence was found for gene transfer between the two $R$. leguminosarum inoculant strains or with any indigenous rhizobia, indicating that such events are relatively uncommon under field conditions.

However, conjugative plasmids, common in the other bacteria that colonised the plant surface, transferred to the GM Pseudomonas fluorescens SBW25 strain at high frequencies under field conditions (M. Bailey). These transfer events coincided with specific periods of plant growth, suggesting that gene transfer was induced by specific environmental stimuli. Subsequent field releases of the GMM carrying one of these plasmids demonstrated not only that transfer was induced coincidentally in bacteria colonising roots and leaves of inoculated plants, but also that plasmid carriage improved host fitness at specific periods of the development of the plant. These data provide a unique insight to the high frequency that bacteria exchange genetic information in the environment. However, these exchanges of information are mediated by specific mobile elements, in this instance plasmids. As a consequence of the in situ uptake of mobile genetic elements the genotype and the phenotype of inoculant strains can change.

\section{EFFICACY OF INOCULANT STRAINS AND IMPACT ON SOIL MICROBIAL COMMUNITIES}

The growth of harmful phytopathogens in the rhizosphere can be controlled by antifungal metabolites such as 2,4-diacetylphloroglucinol (Phl), produced by Pseudomonas fluorescens F113 delivered to the soil as a seed inoculant. The genes for the biosynthesis and regulation of Phl have been elucidated, and genetically modified (GM) strains capable of overproducing Phl created and tested (F. O'Gara). Biosafety evaluations of GM inoculant strains that demonstrated the potential for improved biocontrol of phytopathogens in microcosm-based experiments were conducted in commercial-based field releases under the EU GMO Directive 90/220/EEC. The biosafety assessment of the field released GM Pseudomonas fluorescens F113 strains reported by F. O'Gara centred on evaluating whether the capacity of the GM strain to overproduce Phl had any negative impact on resident microbial communities. The data obtained from the releases, which were the first of their kind with biocontrol of GM-modified strains under the EU Directive, demonstrated that the GM inoculants did not have any negative impact on the overall soil microbiota that was evaluated. Furthermore, the data also demonstrated that the Phl overproducing strains used did not cause any negative impact on the establishment of beneficial AM-fungal interactions. Quorum sensing-related gene expression in the biocontrol strain F113 was shown to involve the participation of additional novel genes that also have homologues in other rhizosphere bacteria.

Seed application of both $P$. putida WCS358r and the PCA-producing GMMs caused a shift in the fungal population of wheat roots, as indicated by cluster analysis of replicate ARDRA-generated profiles of rhizosphere samples (E. Smit). In the field trials of 1997 and 1998, introduction of both the modified and wild type strains resulted in a transient effect on the composition of the rhizosphere fungal microflora. This was most prominent 
Overview of the 7th International Symposium on the biosafety of GMOs

at the beginning of these field trials, when the numbers of introduced bacteria were relatively high, GMM-induced impact on the composition of the fungal microflora lasted longer than the WCS358r-induced impact. This indicates that the PCA produced by the GMMs also affected the composition of the fungal microflora. The detection of PCA in the rhizosphere of GMM-treated plants but not in rhizosphere samples of WCS358-treated plants and control plants supports the role of PCA in these shifts in the fungal microflora. In 1999, introduction of the Phl producing GMM, either as a single application or in combination with the PCA producer, had a longer lasting effect on the rhizosphere fungal microflora. For the same treatments a transient effect was observed on the bacterial microflora. Although it was expected that the intensity of the effects would increase with repeated introduction of the inoculant strains in the same plot, no enhanced effects were observed by repeated introduction.

The investigations with the PCA producing variant of strain SBW25 have confirmed that the GM inocula are highly effective in the control of damping off disease and plant growth promotion in comparison to the unmodified wild type strain. Potential impacts of the inocula on the rhizosphere microbial communities were analysed with a range of cultivation-dependent and independent methods. It was found that disease, plant type and age had a greater effect on the indigenous soil microbial community than the inocula.

\section{CONCLUSIONS}

The field releases performed with GM inocula have shown that the survival and persistence depend on the kind of the inoculant strain, the site characteristics (soil type, climate) and the plant type. If effects on the rhizosphere or bulk soil communities were observed they were mostly transient and minor compared to the effect of plant type and age or the characteristics of the site. The horizontal gene pool of the indigenous bacterial community can change the genotype of the inoculant strain. Most of the presently applied methods to analyse potential impacts on the soil microbial communities provide information on structural diversity. The use of new methodological approaches is required to link structure with function which might also lead to an increased sensitivity of the monitoring techniques. The molecular tools which allow a cultivation-independent analysis of rhizosphere microbial communities were sensitive enough to detect shifts in the composition of bacterial communities during plant growth development, and to show that certain microbial populations are enhanced in their abundance and activity in the rhizosphere in a plant-dependent manner. Monitoring the strain identity, the presence and expression of the genetic modification as well as the fate and activity of inoculant strains in the rhizosphere are important for their successful exploitation. A number of new findings have emerged which will impact strongly on our future approaches to exploiting and environmentally managing microorganisms for societal benefit. The importance of signaling between rhizosphere populations has also been extended by the observation that active signaling systems have the potential to significantly influence the function and coexistence of fungal-bacterial interactions and communities in the rhizosphere. 